\title{
Surgical Leadership Training beyond the Traditional Mentorship Model
}

\author{
Shivangi Saha ${ }^{1}$ \\ ${ }^{1}$ Department of Plastic Reconstructive and Burns Surgery, All India \\ Institute of Medical Sciences, New Delhi, India
}

\begin{abstract}
Address for correspondence Dr. Shivangi Saha, MBBS, MS, Department of Plastic Reconstructive and Burns Surgery, Jai Prakash Narayan Apex Trauma Centre, AlIMS, Room no. 223, Safdarjung Enclave, New Delhi, Delhi 110029, India (e-mail: shivangisaha@gmail.com).
\end{abstract}

Indian J Plast Surg:2020;53:416-418

\begin{abstract}
Keywords

- American society of plastic surgeons

- scholarship

- international trainee

In this article, I reflect on my experience of being awarded the International Resident Travel Scholarship for "Plastic Surgery the Meeting 2019." I was the first Indian to be awarded the scholarship, and it offered me not only monetary assistance but also mentorship for future leadership positions. The award further opened doors for several future opportunities in the form of memberships in the American Society of Plastic Surgery (ASPS) committees and Resident Advisory Board of the prestigious "Plastic and Reconstructive Surgery Journal." I believe this article will make more residents aware and utilize such opportunities for their career development.
\end{abstract}

\section{"Leadership and Learning are Indispensable to Each Other."- John F. Kennedy}

Traditionally, medical school training focuses on imparting knowledge and skills to deliver patient care. Residency polishes the surgical skills while working as a team, but, along the path, there is hardly any training to prepare us for life beyond surgery. When as young surgeons we take on new positions, we feel the need for learning skills outside the confines of the operating room, which would enable us to be future leaders. ${ }^{1}$ Yet, most of us feel inadequately trained to take up this role.

To be adequately trained, we need mentorship in three facets-clinical, research and education (called the triple threats).2,3 Apart from honing our surgical skills, we need to be actively involved in innovation, procure grants for research, publish studies, peer review the work of our colleagues, and be eloquent to communicate our research on larger forums. Good communication and collaboration skills are essential for effective teaching and working as a team. Thus, the surgical skills should complement leadership skills for a coordinated and efficient teamwork to provide safe and quality patient care.

published online

November 30, 2020
DOI https://doi.org/

10.1055/s-0040-1721517

ISSN 0970-0358.
The American Society of Plastic Surgeons (ASPS)/Plastic Surgery Foundation envisions taking the "traditional institution-based mentor-mentee relationship," as one of the key tenets of effective leadership training, to a global platform. ${ }^{4}$ They select nine travel scholars every year (four international and five domestic) for the ASPS International Resident travel scholarship, with the aim to cultivate future leaders amongst Plastic Surgery Residents/Fellows.

This reflection outlines my experience of being the first Indian to be awarded the International Resident travel scholarship for the 2019 session of "Plastic Surgery the Meeting."

I came across this remarkable opportunity while submitting abstracts for the ASPS annual conference on their website. It also mentioned that each institute is only allowed to nominate one resident for the scholarship. The application process involved the submission of letters of recommendations from mentors, a motivation letter, and a curriculum vitae mentioning the involvement in significant leadership positions and the potential to contribute to the ASPS in future. Our selection was based on the leadership potential, geographical location, gender, and ethnic diversity.

(c) 2020. Association of Plastic Surgeons of India.

This is an open access article published by Thieme under the terms of the Creative Commons Attribution-NonDerivative-NonCommercial-License, permitting copying and reproduction so long as the original work is given appropriate credit. Contents may not be used for commercial purposes, or adapted, remixed, transformed or built upon. (https://creativecommons.org/licenses/by-nc-nd/4.0/) Thieme Medical and Scientific Publishers Pvt. Ltd. A-12, 2nd Floor, Sector 2, Noida-201301 UP, India 
The awardees get invited to the annual meeting of the ASPS at Plastic Surgery The Meeting (PSTM). They are awarded a cash prize to cover travel and related expenses, recognized during walk-in slides at the opening ceremony, involved in several special events and committee meetings, and are presented an award at the closing ceremony.

\section{Major Takeaways}

I landed in the vibrant and sun-kissed city of San Diego right on the day of the conference. I was flabbergasted at the sight of all the doyens of Plastic Surgery right in front of me, whom I had read about in landmark articles and textbooks.

At the outset, we were introduced to two American resident mentors, who not only helped us navigate through the conference but also gave us general advice on the training and fellowship system and opportunities within the US.

What awaited us next was the resident scholar luncheon, where we were welcomed by the leadership of the ASPS and its various committee leaders and representatives. At the lunch, all the scholars were formally recognized for their accomplishments. We were also asked to share our career goals as future leaders, current initiatives that we wished to build upon, and how the merits of the program could align to help us accomplish these goals.

\section{Involvement with the ASPS Committees}

During the course of the conference, being a scholar enabled me to participate in many exciting activities such as the stellar opening ceremony and several ASPS committee meetings. We were allowed a glimpse into the functioning of the committees, as a wide array of ASPS leadership committees are open to international resident participation. We were invited as members to contribute to the committees based upon our ideas and vision. The committees on leadership development, resident curriculum development, clinical research and patient safety particularly piqued my interest. I applied for membership in these committees, so that I could have a deeper insight into their functioning and continue to contribute my perspective as an overseas trainee in the years to come.

\section{Networking and Collaborative Research Opportunities}

The award conferred me with recognition and confidence. It provided countless opportunities to network with plastic surgeons from across the globe during the Women Plastic Surgeons networking hour and Young Plastic Surgeons networking hour. It also allowed me to meet and acquaint myself with eight other scholars from various countries around the world, who shared a common vision. I was brimming with new and interesting collaborative research ideas as I returned to my institute. I also built a strong friendship with other individuals and teams, which I am sure will persist over time.

\section{Involvement with the Plastic and Reconstructive Surgery (PRS) Journal-Resident Advisory Board}

A major highlight of the program was our interaction with the representatives from the PRS and PRS Global Open journals, who guided us on ways to get involved with the PRS journal. It required us to participate in the PRS journal's clubs via social media platforms, peer review the manuscripts for the esteemed journal, and contribute our write-ups to them. After coming back from the conference, I began contributing to the journal in various ways. I was mentored on the nuances of the peer review process and, in due course, was also selected to be a part of the resident advisory board of the journal. I coauthored columns like PRS spotlight and wrote for their official blogpost, Resident Chronicles, as well.

\section{Mentors and Mentorship Sessions}

We had a mentoring session on grant writing, where I got an opportunity to be personally mentored on one of my research project proposals by Dr. Paul Cederna, who is a Lead Researcher of the ASPS with numerous awards and grants to his name, and has mentored over a hundred research fellows to date. I also gathered highlights and insights into upcoming research around the world through the excellent presentations given by the other research fellows.

We also participated in a mentorship session with Dr. John W Canady, a former ASPS president, and a global leader and researcher in the treatment of cleft lip/palate. He discussed our career plans, provided us with valuable insights and suggestions, and helped us connect with people who could guide us further on our respective future goals.

\section{The Wow Moments}

I was able to get to know surgeons whom I had only read about in books and admired. They generously allowed me to discuss my queries and learn from their many years of experience. Aesthetic surgery and vascularized composite allotransplantation (VCA) are two areas that fascinate me the most. The conference allowed me to meet and discuss ideas with stalwarts such as Dr. Rod Rohrich and Dr. Scott Levin in their respective fields.

On the finale night of the meeting, all the international attendees received a grand reception held on the USS Midway, which was one of the flagship aircraft carriers of the US Navy after World War II. At the ceremony, we met Professor Peter Neligan, an author to world renowned textbooks, who gave an enthralling musical performance.

I cannot overstate the valuable and multifaceted impact of this experience on my career as a young surgeon. Surely this trip was the most exceptional international experience I have had in my training thus far. I have always aspired to be a leader, and this unique learning experience enabled me to reflect on my leadership abilities and gain confidence. As a recipient of this award, I strongly believe more Indian trainees should utilize this opportunity to navigate the 
evolving demands of a versatile career, fill the critical gap in leadership development during their surgical residency, and enable their professional development as future leaders.

Declarations

The author is a Resident Associate Editor for the Indian Journal of Plastic Surgery.

\section{Conflicts of Interest}

None declared.

\section{References}

1 Patel VM, Warren O, Humphris P, et al. What does leadership in surgery entail? ANZ J Surg 2010;80(12):876-883

2 Addona T, Polcino M, Silver L, Taub PJ. Leadership trends in plastic surgery. Plast Reconstr Surg 2009;123(2):750-753

3 GrigsbyRK,HefnerDS,SoubaWW,KirchDG.Thefuture-oriented department chair. Acad Med 2004;79(6):571-577

4 Rosengart TK, Kent KC, Bland KI, et al. Key tenets of effective surgery leadership: perspectives from the Society of Surgical Chairs Mentorship Sessions. JAMA Surg 2016;151(8):768-770 